\title{
Cloud Computing Adoption in Organisations: Review of Empirical Literature
}

\author{
Haslinda Hassan ${ }^{1, *}$, Mohd Herry Mohd Nasir ${ }^{1}$, Norhaiza Khairudin ${ }^{1}$ \\ ${ }^{1}$ Tunku Puteri Intan Safinaz School of Accountancy, Universiti Utara Malaysia, 06010 Sintok, Kedah, \\ Malaysia
}

\begin{abstract}
This study reviews literature on cloud computing adoption in organisations to identify its influential factors and its operationalisation in prior literature. We classify the factors that influence the cloud computing adoption using the three contexts suggested by the TechnologyOrganisation-Environment (TOE) framework, namely, technology, organisation, and environment. The finding suggests that the influences of these factors vary across studies and most of the studies have operationalised cloud computing adoption using intention to adopt cloud computing or binary variable, rather than the actual use of the technology.
\end{abstract}

\section{Introduction}

Cloud computing technology is becoming ubiquitous and exploited increasingly by organisations to leverage the information technology (IT) opportunities [1] and to stay competitive and innovative [2]. This technology has been claimed as being able to provide economic advantages, such as reducing computing costs, scalability, and flexibility. These advantages are becoming the major drivers for the increasing use of cloud computing in business organisations $[1,3]$.

Cloud computing refers to the use of shared computing resources over the Internet [4]. The National Institute of Standards and Technology (NIST) defines cloud computing as "a model for enabling convenient, on-demand network access to a shared pool of configurable computing resources (e.g. networks, servers, storage, applications, and services) that can be rapidly provisioned and released with minimal management effort or service provider interaction" [5]. This technology evolved through the recent advancements in hardware, virtualisation technology, distributed computing, and service delivery over the Internet [6]. The cloud computing services provide an alternative to the use of local servers' applications [4].

An increasing number of studies are taking place in determining factors that influence cloud computing adoption in business organisations. The studies have explored the importance of technological, organisational, and environmental factors to cloud computing adoption in the organisations, however, their influences vary across studies. Hence, there is a need to analyse the influential factors in different studies to acquire a better understanding of the cloud computing adoption in the organisations. Specifically, this paper attempts to

* Corresponding author: 1ynn@uum.edu.my 
identify the factors that influence the cloud computing adoption in the organisations and to determine how the existing studies operationalise the cloud computing adoption.

The next section presents literature review on cloud computing, focusing specifically on understanding cloud computing, factors influencing the cloud computing adoption in organisations, and the operationalisation of cloud computing adoption. The final section concludes with the study's limitation.

\section{Literature Review}

\subsection{Understanding cloud computing}

The term "cloud" is derived from the idea where users are able to access applications from anywhere in the world on demand [7]. Cloud computing uses ubiquitous resources that can be shared by business users over the Internet, allowing them to communicate with many servers at the same time [2].

There are three types of cloud computing services, namely, Infrastructure-as-a-System (IaaS), Platform-as-a-Service (PaaS), and Software-as-a-Service (SaaS). IaaS is the most basic service level that offers customers the infrastructure services over the Internet, including storage, network, and software. The customer mainly manages the operation of the infrastructure while the provider generally maintains the operations of the data centre [4]. PaaS offers services, such as application design, development, testing, deployment, and programming language hosting tools, in which the access to these services are provided online to customers who desire to build an application for their organisation [3]. Hence, customers who use these PaaS services do not have to buy and manage the underlying infrastructure to develop the application as they are available online. In the SaaS model, users can utilise a hosted set of software that they do not own, but pay for the elements of the utilisation [4]. Customers can install the software according to the types of exclusive and non-exclusive method, including public, private, hybrid, and community clouds [5] and the applications can be used at anytime and anywhere over the Internet [3].

\subsection{Factors influencing cloud computing adoption in organisations}

This study reviews literature on cloud computing adoption in organisations to identify factors that influence the cloud computing adoption in the organisations and to determine how the existing studies operationalise the cloud computing adoption. The search of literature on Google Scholar was conducted on 11th March 2016 where "cloud computing adoption" was used as the keyword. The search was, however, limited to the title of the articles only.

As of the date, we found that there were 352 articles with "cloud computing adoption" at the title of the articles. Nonetheless, several articles with the "adoption of cloud computing" at the title of the articles were also included in the list and were, therefore, considered for review. Many of the studies were, however, excluded from our review due to the studies being exploratory, qualitative in nature, individual used as a unit of analysis, conference papers, lecture notes, and press releases. Articles that did not fall within these criteria are deemed relevant for review. Of the 352, only nine (9) studies focused on the factors that influence cloud computing adoption in organisations and, therefore, selected for review (Table 1). This data indicates that in spite of the increasing attention of researchers to cloud computing, the empirical studies on the factors that influence cloud computing adoption in organisations, are however, limited. It is likely that cloud computing is a relatively recent area of research in the IS discipline [6]. 
Most of the studies were carried out in the Asia-Pacific region [see, for example, 3, 9], Europe [1,6], and North America [10]. Many of them focused on both small and large companies in more than one industry. Only one study emphasised on the SMEs [11] and on a single industry [2].

Technology-organisation-environment (TOE) framework has been widely used in prior studies to examine factors influencing cloud computing adoption in organisations [see, for example, 12]. TOE framework suggests that the process by which an organisation adopts and implements technological innovations is influenced by factors from three contexts: technology $(\mathrm{T})$ - technologies that are relevant to organisations; organisation $(\mathrm{O})$ - the organisation's size, scope, and the amount of slack resources available in the organisations; and environment (E) - external environment in which an organisation conducts its business [8]. Other studies have used a combination of technology acceptance model (TAM)-TOE framework [3], diffusion of innovation (DOI)-TOE [6], institutional theory [9], transaction cost theory [13], and information processing theory [10]. One study, however, did not use any specific theory [11]. TAM model generally explains the individual's behavioural intention to use IT, hence, we argue that the model is more appropriate to be used to measure technology acceptance at the individual level rather than at the organisation. Although mimetic pressure, coercive pressure, and normative pressure (as proposed by the institutional theory) were covered in one study [9], the effects of these factors on cloud computing adoption, however, have not been tested.

Recognising the importance of the TOE framework in prior studies, this framework is used to present the various technological, organisational, and environmental factors found to influence the cloud computing adoption in organisations (see Table 1 for details). Most studies have explored the importance of these factors on cloud computing adoption in their studies, however, their influences on the adoption vary across different industry contexts. We also found that not all studies covered factors from all the three contexts $[9,11,13]$.

From the technological context, three common factors tested in prior studies were relative advantage, compatibility, and complexity. These three factors are derived from Roger's DOI theory [14]. Relative advantage was covered by most of the studies and was found significant. The significant importance of relative advantage indicates that the organisations recognise the relative advantages of cloud computing, such as in reducing IT costs, creating the competitive advantage, and enabling easier access to information. Nonetheless, organisations in high-tech industry have perceived relative advantage as significant but negatively influencing cloud computing adoption. These organisations may have realised the relative advantage of using cloud computing, however, they may have a lower level of cloud computing knowledge [2]. Compatibility was seen as not an important factor to consider cloud computing in all the three studies $[1,2,6]$. Conversely, the significant finding of complexity to cloud computing adoption $[1,3,6,11]$ implies that the organisations have a level of fear and concern regarding the adoption of cloud computing services [1].

From the organisational context, a number of studies on cloud computing adoption have witnessed significant role of top management support on cloud computing adoption in Taiwan [2], Australia [9], and Portugal [6]. The result suggests that top management plays the decision process by demonstrating support in the form of committing financial and organisational resources and engaging in the process [6]. Although the adoption of cloud computing is not limited to large organisations, organisation size was found to be a facilitator of cloud computing adoption [2,6]. Larger organisations with more resources were argued to have more tendencies to adopt cloud computing than smaller organisations. Evidence from the study conducted by Oliveira et al. indicates that firms, with an established technology infrastructure and competent workforce, are better suited for cloud integration [6]. 


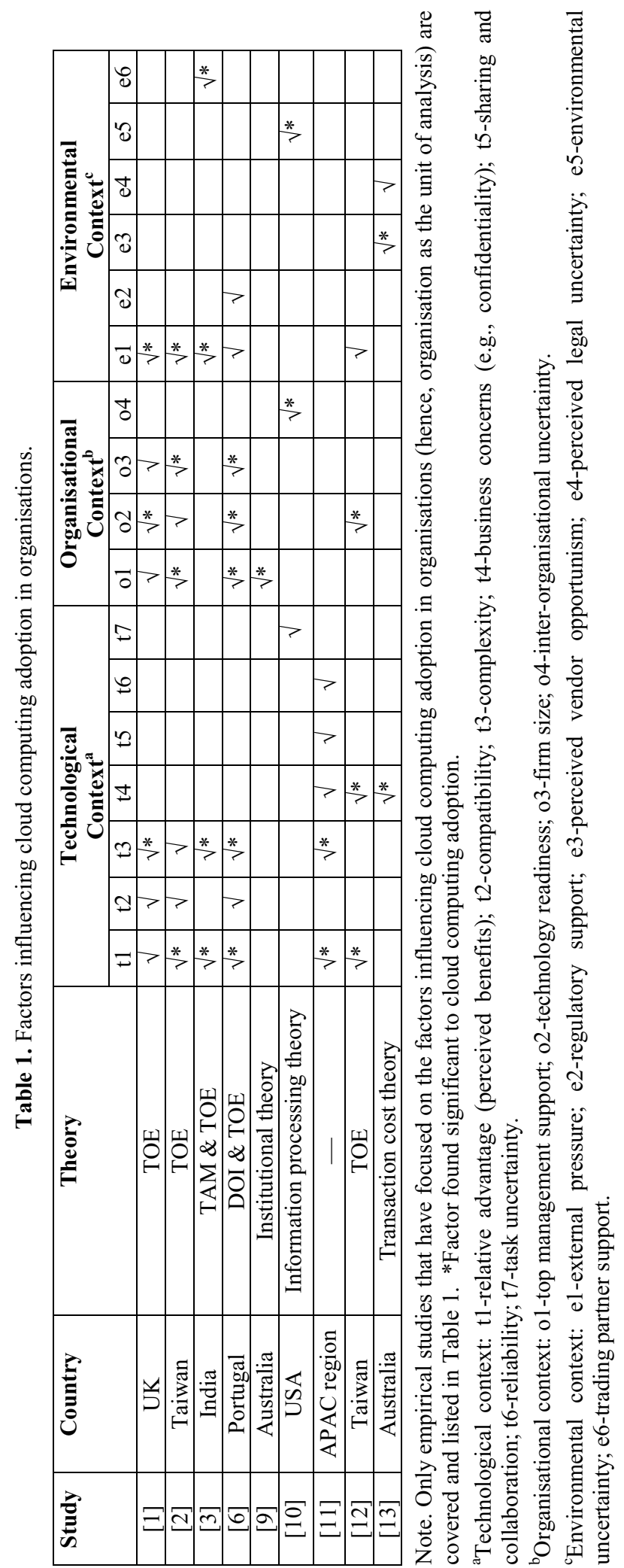


From the environmental context, external pressure was mostly tested and found significant $[1,2,3]$. Complex architecture of cloud computing requires tighter integration of customers, business partners, and suppliers and is influenced by the adoption status of its trading partner [3]. The finding implies that when competitors implement cloud computing as a competitive instrument, other organisations face strong competition, hence, feel pressure to adopt cloud to maintain a competitive edge [3]. Both regulatory support and perceived legal uncertainty were found to be not significant to cloud-computing adoption. This does not necessarily mean that the organisations disregard prevailing standards and regulations, but rather that existing legislation protecting the use of cloud computing has not been earnestly embraced by the organisational decision makers [6].

\subsection{Operationalisation of cloud computing adoption in organisations}

Overall, most of the studies have operationalised cloud computing adoption using adoption intention [see, for example, 3, 10, 12], or binary variable [1, 2] (see Table 2). For example, cloud computing adoption was operationalised using intention to increase the level of computing adoption $[9,13]$ and the summation of the degree of SaaS, PaaS, and IaaS adoption, where three response options (has not adopted; planning to adopt within 12 months; already adopted) were used for each of the three service models [12]. The choice of intention rather than the actual adoption of the technology was due to the relative newness of cloud computing as a business tool [10].

Table 2. Operationalisation of cloud computing adoption.

\begin{tabular}{|c|l|}
\hline Study & \multicolumn{1}{|c|}{ Operationalisation } \\
\hline$[1]$ & Binary variable \\
\hline$[2]$ & Binary variable \\
\hline$[3]$ & Intention to adopt cloud computing \\
\hline$[6]$ & (a) stage of cloud computing adoption; and (b) Intention to adopt cloud \\
\hline$[9]$ & Intention to increase the level of cloud computing adoption \\
\hline$[10]$ & Intention to adopt cloud computing \\
\hline$[11]$ & (a) Its ease of use; (b) its reliability; and (c) security and privacy \\
\hline$[12]$ & Intention to adopt cloud computing \\
\hline$[13]$ & Intention to increase the level of cloud computing adoption \\
\hline
\end{tabular}

Intention to use refers to the degree to which an individual intents to perform a particular behaviour or act. It is, however, argued that the intention to use does not necessary lead to adoption [15]. In addition, measuring technology adoption using binary measures, such as adopt or not adopt cloud computing services, is deemed inadequate as it does not completely capture the reach and richness of the use of IT innovations and cannot inform post-adoptive variability [16].

\section{Conclusion}

This study reviews literature on cloud computing adoption in organisations, focusing specifically on its influential factors and its operationalisation in prior literature. The factors (technology, organisation, and environment) are classified based on the TOE framework. We find that most studies have explored the importance of these factors to cloud computing adoption, nonetheless, their influences vary across studies. Most studies have operationalised cloud computing adoption using intention to adopt or binary variable (adopt or not adopt). The literature chosen for the review is, however, limited to the quantitative studies of cloud computing adoption in the organisations only. 
The authors would like to thank Universiti Utara Malaysia and the Ministry of Higher Education Malaysia for financially supporting this research (FRGS/1/2014/SS05/UUM/02/29).

\section{References}

1. A. Gutierrez, E. Boukrami, R. Lumsden. Technological, organisational and environmental factors influencing managers' decision to adopt cloud computing in the UK. Journal of Enterprise Information Management, 28(6), 788-807 (2015).

2. C. Low, Y. Chen, M. Wu. Understanding the determinants of cloud computing adoption. Industrial Management \& Data Systems, 111(7), 1006-1023 (2011).

3. H. Gangwar, H. Date, R. Ramaswamy. Developing a cloud-computing adoption framework. Global Business Review, 16(4), 632-651 (2015).

4. S. Bhardwaj, L. Jain, S. Jain. Cloud computing: A study of infrastructure as a service (IAAS). International Journal of Engineering and Information Technology, 2(1), 60-63 (2010).

5. P. Mell, T. Grance. The NIST definition of cloud computing. National Institute of Standards and Technology, 53(6), 50 (2009).

6. T. Oliveira, M. Thomas, M. Espadanal. Assessing the determinants of cloud computing adoption: An analysis of the manufacturing and services sectors. Information \& Management, 51(5), 497-510 (2014).

7. N. Sultan. Cloud computing for education: A new dawn? International Journal of Information Management, 30(2), 109-116 (2010).

8. L.G. Tornatzky, M. Fleischer. The process of technological innovation. Lexington, MA: Lexington Books (1990).

9. O.M. Yigitbasioglu. The role of institutional pressures and top management support in the intention to adopt cloud computing solutions. Journal of Enterprise Information Management, 28(4), 579-594 (2015).

10. C.G. Cegielski, L.A. Jones-Farmer, Y. Wu, B.T. Hazen. Adoption of cloud computing technologies in supply chains: An organisational information processing theory approach. The International Journal of Logistics Management, 23(2), 184-211 (2012).

11. P. Gupta, A. Seetharaman, J.R. Raj. The usage and adoption of cloud computing by small and medium businesses. International Journal of Information Management, 33(5), 861-874 (2013).

12. P.F. Hsu, S. Ray, Y.Y. Li-Hsieh. Examining cloud computing adoption intention, pricing mechanism, and deployment model. International Journal of Information Management, 34(4), 474-488 (2014).

13. O. Yigitbasioglu. Modelling the intention to adopt cloud computing services: $A$ transaction cost theory perspective. Australasian Journal of Information Systems, 18(3), 193-210 (2014).

14. E.M. Rogers. Diffusion of innovations (5th Ed.). New York, NY: Free Press (2003).

15. W. Money, A. Turner. Assessing knowledge management system user acceptance with the technology acceptance model. International Journal of Knowledge Management, 1(1), 8-26 (2005).

16. K. Zhu, S. Dong, S.X. Xu, K.L. Kraemer. Innovation diffusion in global contexts: Determinants of post-adoption digital transformation of European companies. European Journal of Information Systems, 15(6), 601-616 (2006). 